\title{
PERAN BIMBINGAN DAN KONSELING ISLAM DALAM PENDIDIKAN
}

\author{
Anas Rohman, M.Pd.
}

\section{Universitas Wahid Hasyim Semarang \\ Email: Rohman_anas2@yahoo.com}

\begin{abstract}
ABSTRAK
Pendidikan pada hakekatnya merupakan usaha sadar untuk mengembangkan kepribadian yang berlangsung seumur hidup baik disekolah maupun madrasah. Pendidikan juga bermakna proses membantu individu baik jasmani dan rohani kearah terbentuknya kepribadian utama pribadi yang berkualitas, dalam konteks Islam pendidikan bermakna bimbingan terhadap pertumbuhan rohani dan jasmani menurut ajaran Islam dengan hikmah mengarahkan, mengajarkan, melatih, mengasuh dan mengawasi beralakunya semua ajaran Islam. Dalam kaitan ini, Peran bimbingan dan konseling Islam dalam pendidikan merupakan usaha membantu individu untuk menjadi manusia yang berkembang dalam hal pendidikan dan membentuk kepribadian yang berguna dalam kehidupannya yang memiliki berbagai wawasan, pandangan, interpretasi, pilihan, penyesuaian dan keterampilan yang tepat berkenan dengan diri sendiri dan lingkungannya. Sehingga urgensi Bimbingan dan Konseling Islam sangat penting guna mencapai perekembangan dan keoptimalan dalam proses pendidikan.
\end{abstract}

Kata kunci: Bimbingan Konseling, Islam, dan Pendidikan

\begin{abstract}
Education is a conscious effort to develop a personality that lasts a lifetime both in school and madrasah. Education also means the process of helping individuals both physically and mentally towards the formation of the main personaly of qualified person, in the context of Islam, education means that the guidance of the spiritual and physical
\end{abstract}


growth according to Islam with wisdom to direct, train, nurture, and oversee the applying of teachings of Islam. In this regards, the role of the guidance and counseling of Islam in education is the effort to help people to be a developing human in terms of education and to form a useful personality in life that have a variety of insights, views, interpretations, choices, adaptation, and the right skills on theirselves and their environment. So, the urgency of Islamic guidance and counseling is very important to achieve the development of educational process.

Keywords: Guidance and Counseling, Islam, and Education.

\section{A. Latar Belakang}

Undang-Undang Republik Indonesia Nomor 20 Tahun 2003 tentang Sistem Pendidikan Nasional pasal 3 menyatakan bahwa Pendidikan Nasional berfungsi mengembangkan kemampuan dan membentuk watak serta peradaban bangsa yang bermartabat dalam rangka mencerdaskan kehidupan bangsa, bertujuan untuk berkembangnya potensi peserta didik agar menjadi manusia yang beriman dan bertakwa kepada Tuhan Yang Maha Esa, berakhlak mulia, sehat, berilmu, cakap, kreatif, mandiri, dan menjadi warga negara yang demokratis serta bertanggung jawab.

Sejalan dengan tujuan umum dari Bimbingan dan Konseling adalah untuk membantu individu memperkembangkan diri secara optimal sesuai dengan tahap perkembangan dan predisposisi yang dimilikinya (seperti kemampuan dasar dan bakat-bakatnya), berbagai latar belakang yang ada (seperti latar belakang keluarga, pendidikan, status sosial ekonomi) serta sesuai dengan tuntutan positif lingkungannya. ${ }^{1}$ Pendidikan pada hakekatnya merupakan usaha sadar untuk mengembangkan kepribadian yang berlangsung seumur

${ }^{1}$ Sutoyo,Anwar.Bimbingan dan Konseling Islami: Teori dan Praktek, (Semarang: Cipta Prima Nusantara.2007) hlm. 24. 
hidup baik di sekolah dan madrasah. Pendidikan juga bermakna proses membantu individu baik jasmani dan rohani kearah terbentuknya kepribadian utama (pribadi yang berkualitas). ${ }^{2}$

Dalam kaitan ini, Peran bimbingan dan konseling Islam dalam pendidikan merupakan usaha membantu individu untuk menjadi manusia yang berkembang dalam hal pendidikan dan membentuk kepribadian yang berguna dalam kehidupannya yang memiliki berbagai wawasan, pandangan, interpretasi, pilihan, penyesuaian dan keterampilan yang tepat berkenan dengan diri sendiri dan lingkungannya. Sehingga urgensi Bimbingan dan Konseling Islam dalam pendidikan sangat penting guna mencapai perekembangan dan keoptimalan dalam proses pendidikan.

\section{B. Definisi Bimbingan dan Konseling Islam}

\section{Sejarah Bimbingan dan Konseling}

Bimbingan dan konseling Islam dalam pendidikan sangat penting sehingga penting sekali untuk memahami secara awal mula perjalanan sejarah terbentuknya layanan bimbingan dan konseling di sekolah. Lahirnya Bimbingan dan konseling dapat di pahami bahwa adanya persoalan-persoalan yang dihadapi masyarakat Barat, yaitu gangguan mental dan penanganan persoalan pendidikan dan pekerjaan di sekolah. ${ }^{3}$ Perkembangan bimbingan dan konseling dalam perjalanannya berdasarkan sejarah sebagai berikut:

${ }^{2}$ Arifin dan Thohirin. Bimbingan dan Konseling di sekolah dan Madrasah: Berbasis Itegrasi, (Jakarta: PT Raja Grafindo Persada), hlm. 5

${ }^{3}$ Latipun, Psikologi Konseling, (Malang: Penerbitan UMM, 2006), hlm. 23 


\section{a. Tahun 1900-1909 (Era Perintisan)}

Tiga tokoh utama pada periode ini adalah Jesse B. Davis, Frank Parsons, dan Clifford Beers. Davis adalah orang pertama yang mengembangkan program bimbingan yang sistematis di sekolah-sekolah. Pada tahun 1907, sebagai pejabat yang bertanggung jawab pada the Grand Rapids (Michigan) school system, ia menyarankan agar guru kelas yang mengajar English Composition untuk mengajar bimbingan satu kali seminggu yang bertujuan untuk mengembangkan karakter dan mencegah terjadinya masalah. Sementara itu, Frank Parsons di Boston melakukan hal yang hampir sama dengan Davis. Ia memfokuskan pada program pengembangan dan pencegahan. Ia dikenal karena mendirikan Boston's Vocational Bureau pada tahun 1908. Berdirinya biro ini mempresentasikan langkah maju diinstitusionalisasikannya bimbingan karier (vocational guidance).

Pada tahun yang sama ketika Frank Parsons mendirikan Vocational Bureau (1908), William Heyle juga mendirikan Community Psychiatric Clinic untuk pertama kalinya. Selanjutnya, The Juvenille Psychopathic institute didirikan untuk memberi bantuan kepada para pemuda di Chicago yang mempunyai masalah. Dalam keadaan tersebut terlibat pula para psikolog, tentu saja tidak mungkin berbicara soal kesehatan mental tanpa melibatkan orang- 
orang yang cukup terkenal, seperti Sigmund Freud dan Joseph Breuer. ${ }^{4}$

b. Tahun 1910-1970

Pada era ini konseling mulai diinstitusionalisasikan dengan didirikannya the National Vocational Guidance Association (NVGA) pada tahun 1913. Selain itu, pemerintah Amerika Serikat mulai memanfaatkan pelayanan bimbingan untuk membantu veteran perang. ${ }^{5}$ Istilah bimbingan (guidance) ini kemudian menjadi label populer bagi gerakan konseling di sekolah-sekolah selama hampir 50 tahunan. Program bimbingan yang terorganisasikan mulai muncul dengan frekuensi tinggi di jenjang SMP sejak 1920-an, dan lebih intensif lagi di jenjang SMA dengan pengangkatan guru BK yang khusus dipisahkan untuk siswa laki-laki dan siswa perempuan. Titik inilah era dimulainya pemfungsian disiplin, kelengkapan daftar hadir selama satu tahun ajaran dan tanggung jawab administrasi lainnya. Akibatnya banyak program pendidikan dekade ini menitikberatkan pada upaya membantu siswasiswa yang mengalami kesulitan akademis atau pribadi dengan mengirimkan mereka ke guru BK untuk mengubah perilaku atau memperbaiki kelemahan.

Gerakan konseling untuk SD juga dimulai di akhir dekade 1920-an hingga awal dekade 1930-an, dipicu oleh

\footnotetext{
${ }^{4}$ Bimo walgito, Bimbingan dan Konseling, (Yogyakarta: Andi Offset, 2010), hlm. 15

${ }^{5}$ Gantina Komalasari dkk, Teori dan Teknik Konseling, (Jakarta: PT. Indeks, 2011), hlm. 38-39
} 
tulisan-tulisan dan kerja keras William Burnham yang menekankan peran guru untuk memajukan kesehatan mental anak yang memang banyak diabaikan diperiode tersebut. ${ }^{6}$ Pada dekade 1940-an ditandai munculnya teori konseling Non-Directive yang dipelopori oleh Carl Rogers. Ia mempublikasikan buku yang berjudul Counseling and Psychotherapy pada tahun 1942. Pada tahun 1950-an muncul pula berbagai organisasi konseling yaitu the American Personnel and Guidance Association (APGA). Selanjutnya disahkannya the National Defense Education Act (NDEA) pada tahun 1958. Undang-undang ini memberikan dana bagi sekolah untuk meningkatkan program konseling sekolah. Konseling mulai melakukan diversifikasi ke area yang lebih luas diawali pada tahun 1970. Konseling mulai berkembang di luar sekolah seperti di lembaga-lembaga komunitas dan pusat-pusat kesehatan mental. $^{7}$

c. Tahun 1980 -an

Dekade ini profesi konseling sudah mulai berkembang dengan munculnya standarisasi training dan sertifikasi. Pada tahun 1981 dibentuk the Council for Accreditation of Counseling and Related Educational Program (CACREP). CACREP berfungsi untuk melakukan standarisasi pada program pendidikan konseling di tingkat master dan doktor

\footnotetext{
${ }^{6}$ Robert L. Gibson dan Marianne H. Mitchell, Bimbingan dan Konseling, (Yogyakarta: Pustaka Pelajar, 2010), hlm. 13-14

${ }^{7}$ Gantina Komalasari dkk, Teori dan Teknik Konseling, (Jakarta: PT. Indeks, 2011), hlm. 39
} 
pada bidang konseling sekolah, konseling komunitas, konseling kesehatan mental, konseling perkawinan dan keluarga, dan konseling di Perguruan Tinggi.

d. Tahun 1990-an

Pada akhir ke 19-an, spesialis psikiatri telah mendapat tempat berdampingan dengan spesialis pengobatan lain. Dengan makin stabilnya posisi psikiatri dalam penanganan gangguan psikologis atau yang lebih dikenal dengan sakit mental, muncullah psikiatri sebagai spesialisasi baru. Spesialisasi baru ini dipelopori oleh Van Ellenberger Renterghem dan Van Eeden. ${ }^{8}$

Selama tahun 1980-an dan 1990-an, sejumlah permasalahan sosial mempengaruhi anak-anak yang pada gilirannya mengakselerasi pertumbuhan konseling. Isu-isu seperti penyalah-gunaan obat, penganiayaan anak, pelecehan seksual dan pengabaian anak, plus meningkatnya minat dan atensi, bagi pencegahannya, mengarah kepada pemandatan konseling. ${ }^{9}$

\section{Bimbingan dan Konseling di Indonesia}

Diawali dari dimasukkannya Bimbingan dan Konseling (dulunya Bimbingan dan Penyuluhan) pada setting sekolah. Pemikiran ini diawali sejak tahun 1960. Hal ini merupakan salah satu hasil Konferensi Fakultas Keguruan dan Ilmu Pendidikan (disingkat FKIP, yang kemudian menjadi IKIP) di Malang tanggal 20 - 24 Agustus 1960. Perkembangan berikutnya tahun

${ }^{8}$ Ibid....., hlm. 40

${ }^{9}$ Robert L. Gibson dan Marianne H. Mitchell, Bimbingan dan hlm. 23 
1964 IKIP Bandung dan IKIP Malang mendirikan jurusan Bimbingan dan Penyuluhan. Tahun 1971 beridiri Proyek Perintis Sekolah Pembangunan (PPSP) pada delapan IKIP yaitu IKIP Padang, IKIP Jakarta, IKIP Bandung, IKIP Yogyakarta, IKIP Semarang, IKIP Surabaya, IKIP Malang, dan IKIP Menado. Melalui proyek ini Bimbingan dan Penyuluhan dikembangkan, juga berhasil disusun "Pola Dasar Rencana dan Pengembangan Bimbingan dan Penyuluhan "pada PPSP. Lahirnya Kurikulum 1975 untuk Sekolah Menengah Atas didalamnya memuat Pedoman Bimbingan dan Penyuluhan.

Tahun 1978 diselenggarakan program PGSLP dan PGSLA Bimbingan dan Penyuluhan di IKIP (setingkat D2 atau D3) untuk mengisi jabatan Guru Bimbingan dan Penyuluhan di sekolah yang sampai saat itu belum ada jatah pengangkatan guru BP dari tamatan S1 Jurusan Bimbingan dan Penyuluhan. Pengangkatan Guru Bimbingan dan Penyuluhan di sekolah mulai diadakan sejak adanya PGSLP dan PGSLA Bimbingan dan Penyuluhan. Keberadaan Bimbingan dan Penyuluhan secara legal formal diakui tahun 1989 dengan lahirnya SK Menpan No 026/Menp an/1989 tentang Angka Kredit bagi Jabatan Guru dalam lingkungan Departemen Pendidikan dan Kebudayaan. Di dalam Kepmen tersebut ditetapkan secara resmi adanya kegiatan pelayanan bimbingan dan penyuluhan di sekolah. Akan tetapi pelaksanaan di sekolah masih belum jelas seperti pemikiran awal untuk mendukung misi sekolah dan membantu peserta didik untuk mencapai tujuan pendidikan mereka. 
Sampai tahun 1993 pelaksanaan Bimbingan dan Penyuluhan di sekolah tidak jelas, parahnya lagi pengguna terutama orang tua murid berpandangan kurang bersahabat dengan BP. Muncul anggapan bahwa anak yang ke BP identik dengan anak yang bermasalah, kalau orang tua murid diundang ke sekolah oleh guru BP dibenak orang tua terpikir bahwa anaknya di sekolah mesti bermasalah atau ada masalah. Hingga lahirnya SK Menpan No. 83/1993 tentang Jabatan Fungsional Guru dan Angka Kreditnya yang di dalamnya termuat aturan tentang Bimbingan dan Konseling di sekolah. Ketentuan pokok dalam SK Menpan itu dijabarkan lebih lanjut melalui SK Mendikbud No 025/1995 sebagai petunjuk pelaksanaan Jabatan Fungsional Guru dan Angka Kreditnya. Di Dalam SK Mendikbud ini istilah Bimbingan dan Penyuluhan diganti menjadi Bimbingan dan Konseling di sekolah dan dilaksanakan oleh Guru Pembimbing. Di sinilah pola pelaksanaan Bimbingan dan Konseling di sekolah mulai jelas. ${ }^{10}$

\section{Pengertian Bimbingan dan Konseling}

Undang-Undang Sistem Pendidikan Nasional No. 20 tahun 2003 pasal 3 menyatakan bahwa Pendidikan Nasional berfungsi mengembangkan kemampuan dan membentuk watak serta peradaban bangsa yang bermartabat dalam rangka mencerdaskan kehidupan bangsa, bertujuan untuk berkembangnya potensi peserta didik agar menjadi manusia yang beriman dan bertakwa kepada Tuhan Yang Maha Esa, berakhlak mulia, sehat, berilmu,

${ }^{10} \mathrm{http} / / /$ belajarpsikologi.com/sejarah-lahirnya-bimbingan-dan-konseling/ dalam google diakses tanggal 25 Maret 2016. 
cakap, kreatif, mandiri, dan menjadi warga negara yang demokratis serta bertanggung jawab. Sejalan dengan tujuan bimbingan berdasarkan pasal 27 peraturan pemerintah No. 29/1990 "Bimbinganmerupakan bantuan yang diberikan kepada siswa dalam rangka upaya penemuan pribadi, mengenal lingkungan dan merencanakan masa depan."

Anwar Sutoyo menjelaskan bahwa layanan bimbingan dan konseling Islami adalah Upaya membantu individu belajar mengembangkan fitrah dan atau kembali kepada fitrah dengan cara memberdayakan (empowering) iman, akal, dan kemauan yang dikaruniakan oleh Allah kepadanya untuk mempelajari tuntunan Allah dan Rasulnya, agar fitrah yang ada pada individu berkembang dengan benar dan kokoh sesuai dengan tuntunan Allah SWT. ${ }^{11}$

Menurut Muhammad Surya, bimbingan adalah suatu proses pemberian bantuan yang terus-menerus dan sistematis dari pembimbing kepada yang dibimbing agar tercapai kemandirian dalam pemahaman diri dan perwujudan diri, dalam mencapai tingkat perkembangan yang optimal dan penyesuain diri dengan lingkungannya. ${ }^{12}$

Menurut Prayitno dan Erman Amti, merumuskan arti Bimbingan adalah proses pemberian bantuan yang dilakukan oleh orang yang ahli kepada seseorang atau beberapa orang individu, baik anak-anak, remaja, maupundewasa, agar orang

\footnotetext{
${ }^{11}$ Anwar Sutoyo. Bimbingan dan Konseling Islami. (Yogyakarta: Pustaka pelajar, 2007), hlm. 24-25

${ }^{12}$ Mohammmad Surya, Psikologi konseling, (Bandung: Pustaka Bani Quraisy, 2003), hlm. 2
} 
yang dibimbing dapat mengembangkan kemampuan dirinya sendiri dan mandiri, dengan memanfaatkan kekuatan individu dan sarana yang ada dan dapat dikembangkan berdasarkan norma-norma yangberlaku. ${ }^{13}$

\section{Islam}

Istilah Islam dalam wacana studi Islam berasal dari bahasa arab dalam bentuk mashdar yang secara harfiyah berarti selamat, sentosa dan damai. Dari kata kerja salima diubah menjadi bentuk aslama yang berarti berserah diri. Dengan demikian arti pokok Islam secara kebahasaan adalah ketundukan, keselamatan, dan kedamaian ${ }^{14}$ Secara terminologis, Ibnu Rajab merumuskan pengertian Islam, yakni: Islam ialah penyerahan, kepatuhan dan ketundukan manusia kepada Allah swt. Hal tersebut diwujudkan dalam bentuk perbuatan.

Syaikh Ahmad bin Muhammad Al-Maliki al-Shawi mendefinisikan Islam dengan rumusan Islam yaitu: aturan Ilahi yang dapat membawa manusia yang berakal sehat menuju kemaslahatan atau kebahagiaan hidupnya di dunia dan akhiratnya ${ }^{15}$ Pendapat lain menyatakan bahwa Islam adalah agama yang dibawa oleh para utusan Allah dan disempurnakan oleh rasullullah SAW yang memiliki sumber pokok al-Qur'an

${ }^{13} \mathrm{P} r$ a y i $\mathrm{n}$ o, E r m a $\mathrm{n}$ A $\mathrm{m} \mathrm{t} \mathrm{i}$, Dasar-daras Bimb ingan dan Konseling,, ( $\mathrm{J}$ a k a r t a : $\mathrm{Rin} \mathrm{e} \mathrm{k} \mathrm{a} \mathrm{Ci} \mathrm{p} \mathrm{t} \mathrm{a,} 2004$ ), $\quad$ h $1 \mathrm{~m}$. 99.

${ }^{14}$ Asy`ari, Ahm dkk., Pengantar Studi Islam (Surabaya: IAIN Sunan Ampel, 2004), hlm. 2

${ }^{15}$ Ahmad bin Muhammad al-Mali al-Shawi, Syarh al-Shawi ‘ala Auhar alTauhid, tk, hlm. 62 . 
dan Sunnah Rasullullah SAW sebagai petunjuk umat Islam sepanjang masa. ${ }^{16}$

Sehingga dapat di tarik kesimpulan pengertian Islam adalah berserah diri, ketundukan, keselamatan, dan kedamaian yang dibawa oleh nabi Muhammad SAW yang memiliki sumber pokok al-Qur'an dan Sunnah untuk beribadah kepada Allah.

\section{Bimbingan dan Konseling Islam}

Beberapa pengertian yang sudah dijelaskan di atas, dapat dikaitkan satu dengan lainnya sehingga menjadi sebutan Bimbingan Konseling Islam yang mempunyai arti bantuan yang diberikan kepada siswa dalam rangka upaya penemuan pribadi, mengenal lingkungan dan merencanakan masa depan dalam hal membantu individu belajar mengembangkan fitrah dan atau kembali kepada fitrah dengan cara memberdayakan (empowering) iman, akal, dan kemauan yang dikaruniakan oleh Allah kepadanya untuk mempelajari tuntunan Allah dan Rasulnya, agar fitrah yang ada pada individu berkembang dengan benar dan kokoh sesuai dengan tuntunan Allah SWT, sehingga proses pemberian bantuan yang terus-menerus dan sistematis dari pembimbing kepada yang dibimbing agar tercapai kemandirian.

Pandangan Farid Hariyanto (Anggota IKI jogjakarta) dalam makalahnya mengatakan bahwa bimbingan dan konseling dalam Islam adalah landasan berpijak yang benar tentang bagaimana proses konseling itu dapat berlangsung baik dan

16 Aswadi, http://komunitaskalikidang.blogspot.co.id/2013/05/bimbingan-dankonseling-Islami.html diakses dari google pukul 10:54. 
menghasilkan perubahan-perubahan positif pada klien mengenai cara dan paradigma berfikir, cara menggunakan potensi nurani, cara berperasaan, cara berkeyakinan dan cara bertingkah laku berdasarkan wahyu dan paradigma kenabian (Sumber Hukum Islam). ${ }^{17}$

\section{Tujuan Bimbingan Konseling Islam}

Secara umum tujuan bimbingan konseling Islam adalah untuk membantu individu mewujudkan dirinya sebagai manusia seutuhnya agar mencapai kebahagiaan hidup di dunia dan di akhirat. Sedangkan tujuan dari bimbingan dan konseling Islam sebagai berikut: ${ }^{18}$

1. Memperoleh pemahaman yang lebih baik terhadap dirinya.

2. Mengarahkan dirinya sesuai dengan potensi yang dimilikinya kearah tingkat perkembangan yang optimal.

3. Mampu memecahkan sendiri masalah yang dihadapinya.

4. Mempunyai wawasan yang lebih realistis serta penerimaan yang objektif tentang dirinya.

5. Dapat menyesuaikan diri secara lebih efektif baik terhadap dirinya maupun lingkungannya sehingga memperoleh kebahagiaan dalam hidupnya.

6. Mempunyai taraf aktualisasi diri sesuai dengan potensi yang dimilikinya.

7. Terhindar dari gejala-gejala kecemasan dan perilaku salah suai.

Menurut Tohirin Dalam Islam, individu yang ingin dicapai seperti yang disebutkan dalam tujuan bimbingan dan konseling

\footnotetext{
${ }^{17}$ Imam Sayuti Farid, Pokok-Pokok Bahasan Tentang Bimbingan Penyuluhan Agama Sebagai Teknik Dakwah, tk, hlm. 29

${ }^{18}$ Arifin dan Thohirin. Bimbingan dan Konseling di sekolah hlm.36-37 
diatas identik dengan individu yang kaffah atau insan kamil yang mempunyai kepribadian sehat baik rohani (mental atau psikis) dan jasmaninya (fisiknya).

Sedangkan dalam bukunya bimbingan dan konseling dalam Islam, Aunur Rahim Faqih membagi tujuan Bimbingan dan Konseling Islam dalam tujuan umum dan tujuan khusus: ${ }^{19}$

1. Tujuan umumnya adalah membantu individu mewujudkan dirinya sebagai manusia seutuhnya agar mencapai kebahagiaan hidup di dunia dan di akhirat.

2. Tujuan khususnya adalah:

a. Membantu individu untuk mengatasi masalah yang dihadapinya

b. Membantu individu memelihara dan mengembangkan situasi dan kondisi yang baik atau yang tetap baik menjadi tetap baik atau menjadi lebih baik, sehingga tidak akan menjadi sumber masalah bagi dirinya dan orang lain.

\section{Peran Bimbingan dan Konseling Islam dalam Pendidikan}

Pendidikan pada hakekatnya merupakan usaha sadar untuk mengembangkan kepribadian yang berlangsung seumur hidup baik disekolah maupun madrasah. Pendidikan juga bermakna proses membantu individu baik jasmani dan rohani kearah terbentuknya kepribadian utama pribadi yang berkualitas, dalam konteks Islam pendidikan bermakna bimbingan terhadap pertumbuhan rohani dan jasmani menurut ajaran Islam dengan hikmah mengarahkan,

${ }^{19}$ Farid Hariyanto, Bimbingan dan Konseling di sekolah dan Madrasah (berbasis itegrasi). Jakarta: PT Raja grafindo. 2007 hlm 5. dalam makalah seminar Bimbingan Dan Konseling Agama .Jakarta: 2007 .hlm .2 
mengajarkan, melatih, mengasuh dan mengawasi beralakunya semua ajaran Islam. $^{20}$

Bimbingan dan Konseling memahami individu yang berada dalam proses berkembang atau menjadi (on becaming), yaitu berkembang ke arah kematangan atau kemandirian. Untuk mencapai kematangan dan kemandirian tersebut, konseli memerlukan bimbingan karena mereka masih kurang memiliki pemahaman atau wawasan tentang dirinya dan lingkungannya, juga pengalaman dalam menentukan arah kehidupannya. Disamping itu terdapat suatu keniscayaan bahwa proses perkembangan konseli tidak selalu berlangsung secara mulus, atau bebas dari masalah. Dengan kata lain proses perkembangan itu tidak selalu berjalan dalam arus linier, lurus, atau searah dengan potensi, harapan dan nilai-nilai yang dianut.

Perkembangan konseling tidak lepas dari pengaruh lingkungan, baik fisik, psikis, maupun social. Sifat yang melekat pada lingkungan adalah perubahan. Perubahan yang terjadi dalam lingkungan dapat mempengaruhi gaya hidup (life style) warga masyarakat. Apabila perubahan yang terjadi itu sulit diprediksi, atau diluar jangkauan kemampuan, maka akan melahirkan kesenjangan perkembangan perilaku konseling, seperti terjadinya stagnasi (kemandekan) perkembangan, masalah-masalah pribadi atau penyimpangan perilaku. Iklim lingkungan kehidupan yang kurang sehat, seperti maraknya tayangan televisi dan media-media lain, penyalahgunaan alat kontraspsi, ketidakharmonisan dalam kehidupan

${ }^{20}$ Arifin dalam Tohirin. Bimbingan dan Konseling di sekolah dan hlm 5 
keluarga, dan dekandensi moral orang dewasa ini mempengaruhi perilaku atau gaya hidup konseli (terutama pada usia remaja) yang cenderung menyimpang dari kaidah-kaidah moral (akhlak yang mulia), seperti pelanggaran tata tertib, pergaulan bebas, tawuran, dan kriminalitas.

Upaya menangkal dan mencegah perilaku-perilaku yang tidak diharapkan seperti yang disebutkan, adalah mengembangkan potensi konseli dan memfasilitasi mereka secara sistematik dan terprogram untuk mencapai standar kompetensi kemandirian. Dengan demikian, pendidikan yang bermutu efektif dan ideal adalah pendidikan yang tidak mengesampingkan bimbingan dan konseling. Pendidikan yang hanya melaksanakan bidang administratif dan instruksional dengan mengabaikan bimbingan dan konseling, hanya akan menghasilkan konseli yang pintar dan terampil dalam aspek akademik, tetapi kurang memiliki kemampuan atau kematangan dalam aspek kepribadian.

Bimbingan dan konseling tujuan pendidikan yang dicitacitakan itu bimbingan konseling disekolah di orientasikan kepada upaya memfasilitasi perkembangan potensi konseli, yang meliputi aspek pribadi, belajar dan karir, atau terkait dengan perkembangan konseli sebagai makhluk yang berdimensi biopsikososiospiritual (biologis, psikis, sosial dan spiritual). ${ }^{21}$ Sesuai undang-undang nomor 20 tahun 2003, yaitu:

1. Beriman dan bertaqwa terhadap tuhan yang maha esa

${ }^{21}$ Aunur Rahim Faqih, Bimbingan dan Konseling dalam Islam, (Jakarta: UII press, 2001), hlm. 35-36 
2. Berakhlak mulia

3. Memiliki pengetahuan dan keterampilan

4. Memiliki kesehatan jasmani dan rohani

5. Memiliki kepribadian yang mantap dan kebangsaan

6. Memiliki rasa tanggung jawab kemasyarakatan dan kebangsaan.

\section{E. Simpulan}

Peranan bimbingan dan konseling Islam dalam pendidikan merupakan usaha membantu individu untuk menjadi manusia yang berkembang dalam hal pendidikan dan membentuk kepribadian yang berguna dalam kehidupannya yang memiliki berbagai wawasan, pandangan, interpretasi, pilihan, penyesuaian dan keterampilan yang tepat berkenan dengan diri sendiri dan lingkungannya. Sehingga urgensi Bimbingan dan Konseling Islam sangat penting guna mencapai perekembangan dan keoptimalan dalam proses pendidikan.

Bimbingan dan Konseling Islam adalah suatu proses pemberian bantuan secara terus menerus dan sistematis terhadap layanan bimbingan dan konseling Islami yang mengupayakan membantu individu belajar mengembangkan fitrah dan atau kembali kepada fitrah dengan cara memberdayakan (empowering) iman, akal, dan kemauan yang dikaruniakan oleh Allah kepadanya untuk mempelajari tuntunan Allah dan Rasulnya, agar fitrah yang ada pada individu berkembang dengan benar dan kokoh sesuai dengan tuntunan Allah SWT, sehingga orang yang sedang mengalami masalah dapat memahami dirinya dan mampu memecahkan masalah yang dihadapinya sehingga bahagia dunia ahirat sesuai dengan ketentuan dan petunjuk Allah dan Rasul-Nya. 
Tujuan Bimbingan dan Konseling Islam dalam pendidikan dibagi menjadi tujuan umum dan tujuan kusus. Tujuan umumnya adalah membantu individu mewujudkan dirinya sebagai manusia seutuhnya agar mencapai kebahagiaan hidup di dunia dan di akherat.Tujuan khususnya adalah: 1. Membantu individu untuk mengatasi masalah yang dihadapinya. 2. Membantu individu memelihara dan mengembangkan situasi dan kondisi yang baik atau yang tetap baik menjadi tetap baik atau menjadi lebih baik, sehingga tidak akan menjadi sumber masalah bagi dirinya dan orang lain. 3 . Bimbingan dan Konseling Islam memandang individu sebagai seorang yang berada dalam proses berkembang yaitu berkembang ke arah kematangan atau kemandirian. Untuk mencapai kematangan dan kemandirian tersebut individu memerlukan bimbingan dan konseling Islam, agar memiliki pemahaman atau wawasan tentang dirinya dan lingkungannya, juga pengalaman menentukan arah kehidupannya. Disaming itu terdapat suatu keniscayaan bahwa proses perkembangan peserta didik tidak selalu berlangsung mulus,atau bebas dari masalah sehingga searah dengan potensi, harapan dan nilai-nilai yang dianut.

\section{DAFTAR PUSTAKA}

Al-Shawi, Ahmad bin Muhammad al-Mali, Syarh al-Shawi `ala Auhar al-Tauhid. Tk.

Anwar, Sutoyo. 2007. Bimbingan dan Konseling Islami. Yogyakarta: Pustaka pelajar. 
Arifin dan Thohirin. Bimbingan dan Konseling di sekolah dan Madrasah (berbasis Itegrasi). Jakarta: PT Raja Grafindo Persada.

Aswadi, http://komunitaskalikidang.blogspot.co.id/2013/05/bimbingandan-konseling-Islami.html diakses dari google pukul 10:54.

Asy`ari, Ahm dkk. 2004. Pengantar Studi Islam. Surabaya: IAIN Sunan Ampel, Ahmad bin Muhammad al-Mali al-Shawi, Syarh al-Shawi ‘ala Auhar al-Tauhid.

Aunur, Rahim Faqih.2001. Bimbingan dan Konseling dalam Islam. Jakarta: UII press.

Budiarianto, Ahmad, dalam Http://.blogspot.co.id/2011/04/makalah-bkIslam.html, diakses dari google pukul 11:11

Direktorat Jenderal Peningkatan Mutu Pendidikan dan Tenaga Kependidikan depaartemen Pendidikan Nasional, 2007. Ramburambu Penyelenggaraan Bimbingan dan Konseling dalam Jalur Pendidikan Formal. Jakarta.

Farid, Imam Sayuti.2002. Pokok-Pokok Bahasan Tentang Bimbingan Penyuluhan Agama Sebagai Teknik Dakwah. Bandung: Alfabetha.

Gibson, Robert L. dan Marianne H. Mitchell, 2010. Bimbingan dan Konseling. Yogyakarta: Pustaka Pelajar.

Hariyanto, Farid, 2007. Bimbingan dan Konseling di sekolah dan Madrasah : berbasis itegrasi, Jakarta: PT Raja grafindo.

, 2007. Makalah dalam Seminar Bimbingan dan Konseling Agama Jakarta: Admin.

, Http://belajarpsikologi.com/sejarah-lahirnya-bimbingan-dankonseling/ diakses dari google tanggal 25 Maret 2016 pada pukul 11.30 .

Https://Konserissumbar.Wordpress.Com/2015/12/01/Tujuan-BimbinganDan-Konseling-Islami/ diakses dari google pada pukul 11:51 
Komalasari, Gantina dkk., 2010. Teori dan Teknik Konseling.Jakarta: PT. Indeks.

Latipun. 2006. Psikologi Konseling, Malang: Penerbitan UMM.

Mubarok, Ahmad, 2002, Al-Irsyad an Nafsy, Konseling Agama Teori dan Kasus. Yogyakarta: Fajar Pustaka Baru.

Prayitno dan Erman Amti, 2004. Dasar-daras Bimb ingan dan Konseling.Jakarta: Rineka Cipta.

Surya, Mohammad.2003. Psikologi konseling,. Bandung: Pustaka Bani Quraisy.

Walgito, Bimo, Bimbingan dan Konseling. Yogyakarta: Andi Offset. 